\title{
Erratum: PU.1 is a major downstream target of AML1 (RUNX1) in adult mouse hematopoiesis
}

Gang Huang, Pu Zhang, Hideyo Hirai, Shannon Elf, Xiaomei Yan, Zhao Chen, Steffen Koschmieder, Yutaka Okuno, Tajhal Dayaram, Joseph D Growney, Ramesh A Shivdasani, D Gary Gilliland, Nancy A Speck, Stephen D Nimer \& Daniel G Tenen Nature Genetics 40, 51-60 (2008); published online 11 November 2007; corrected after print 23 January 2008

In the version of this article initially published, the affiliation for Stephen D Nimer was incorrect. Dr. Nimer is affiliated with the Division of Hematologic Oncology, Memorial Sloan-Kettering Cancer Center, New York, and not with Kyoto Prefectural University of Medicine. The error has been corrected in the PDF version of the article.

\section{Erratum: Mutations in TTBK2, encoding a kinase implicated in tau phosphorylation, segregate with spinocerebellar ataxia type 11}

Henry Houlden, Janel Johnson, Christopher Gardner-Thorpe, Tammaryn Lashley, Dena Hernandez, Paul Worth, Andrew B Singleton, David A Hilton, Janice Holton, Tamas Revesz, Mary B Davis, Paolo Giunti \& Nicholas W Wood

Nature Genetics 39, 1434-1436 (2007); published online 25 November 2007

The first name of an author was misspelled. The correct author name is Paola Giunti.

\section{Corrigendum: Mutations in smooth muscle $\alpha$-actin (ACTA2) lead to thoracic aortic aneurysms and dissections}

\footnotetext{
Dong-Chuan Guo, Hariyadarshi Pannu, Van Tran-Fadulu, Christina L Papke, Robert K Yu, Nili Avidan, Scott Bourgeois, Anthony L Estrera, Hazim J Safi, Elizabeth Sparks, David Amor, Lesley Ades, Vivienne McConnell, Colin E Willoughby, Dianne Abuelo, Marcia Willing, Richard A Lewis, Dong H Kim, Steve Scherer, Poyee P Tung, Chul Ahn, L Maximilian Buja, C S Raman, Sanjay S Shete \& Dianna M Milewicz Nature Genetics 39, 1488-1493 (2007); published online 11 November 2007; corrected after print 23 January 2008

In the version of this article initially published, the affiliation for C S Raman was incorrect. Dr. Raman is affiliated with the Department of Biochemistry and Molecular Biology at the University of Texas Health Science Center, and not with the Structural Biology Center. The error has been corrected in the PDF version of the article.
} 